\title{
Interferon- $\gamma$ in 388 immunocompromised and immunocompetent patients for diagnosing pleural tuberculosis
}

\author{
V. Villena*, A. López-Encuentra*, J. Echave-Sustaeta*, P. Martín-Escribano*, \\ B. Ortuño-de-Solo**, J. Estenoz-Alfaro**
}

Interferon- $\gamma$ in 388 immunocompromised and immunocompetent patients for diagnosing pleural tuberculosis. V. Villena, A. López-Encuentra, J. Echave-Sustaeta, P. MartínEscribano, B. Ortuño-de-Solo, J. Estenoz-Alfaro. @ ERS Journals Ltd 1996.

ABSTRACT: The level of interferon- $\gamma($ IFN- $\gamma)$ in pleural fluid has been reported to be increased in pleural tuberculosis. Nevertheless, its diagnostic value has not yet been well-established, and immunocompromised patients have not previously been evaluated. The aim of this study was to determine the value of the IFN- $\gamma$ level in pleural fluid for diagnosing tuberculous pleurisy in immunocompetent and immunocompromised patients.

Three hundred and eighty eight consecutive patients were studied prospectively (73 with tuberculous pleural effusions, including nine with concurrent human immunodeficiency virus (HIV) infection and one after liver transplantation, and 315 with nontuberculous effusions). IFN $-\gamma$ was measured by radioimmunoassay.

The sensitivity of the test, using a $3.7 \mathrm{U} \cdot \mathrm{mL}^{-1}$ cut-off point, was $0.99(95 \%$ confidence interval (95\% CI) 0.93-1.00) and the specificity was 0.98 (95\% CI 0.96-1.00). The sensitivity of the test did not differ in HIV-positive and HIV-negative patients. Patients with lymphoma, vasculitis or vascular connective tissue disease did not have abnormal IFN- $\gamma$ values.

In conclusion, the level of interferon- $\gamma$ in pleural fluid is a very good diagnostic marker of tuberculous pleural effusion, even in immunocompromised patients.

Eur Respir J., 1996, 9, 2635-2639.
Tuberculous pleural effusion is probably caused by a delayed hypersensitivity response to rupture of a subpleural caseous focus into the pleural space [1]. Several cytokines are involved in this immunoreaction [2-4]. The diagnosis of pleural tuberculosis is usually obtained by culture of the pleural fluid or tissue [5], or by the presence of granulomas in a pleural biopsy $[1,6]$ in the absence of other pleural granulomatous disease. Nevertheless, the sensitivity of these tests is not high and pleural biopsy often has to be repeated [6].

In recent years, several biological parameters have been found to be diagnostic markers of tuberculous pleurisy [7-12]. Interferon- $\gamma(\mathrm{IFN}-\gamma)$ is a lymphokine produced by T-lymphocytes in response to antigen stimulation [13]. It enhances macrophage phagocytic activity against mycobacteria, and increases in tuberculous pleuritis as a result of local production $[2,14]$. Nevertheless, its diagnostic value has not previously been studied in immunocompromised patients.

The aim of this study was to determine the value of the level of IFN- $\gamma$ in pleural fluid for diagnosing tuberculous pleurisy in immunocompetent and immunocompromised patients.
*Respiratory and **Nuclear Medicine Depts, Hospital Universitario 12 de Octubre, Madrid, Spain.

Correspondence: V. Villena

Servicio de Neumologia

Hospital 12 de Octubre

Carretera de Andalucía Km 5.4

28041 Madrid

Spain

Keywords: Interferon- $\gamma$

pleural effusion

tuberculosis (pleural)

Received: November 171995

Accepted after revision August 161996

This study was supported in part by grants from FIS 92/0381.

\section{Patients}

All of the patients with pleural effusion assessed in our service from December 1, 1991 to March 31, 1995, in whom a diagnostic thoracentesis had yielded enough pleural fluid, were prospectively studied. All patients were studied according to the same diagnostic procedure [15]. Cases in which the diagnosis was difficult were discussed jointly by at least eight of the participating physicians. A periodic radiological and clinical follow-up (every 3 months for the first 6 months, and every 6 months thereafter) was maintained for patients with unknown aetiology. The clinical physicians were unaware of the IFN- $\gamma$ level, and the laboratory physicians did not know the clinical diagnosis.

The patients were classified into different diagnostic groups according to the following criteria:

1. Tuberculous pleural effusion. These patients had a positive Löwenstein culture of pleural fluid or tissue, and/or granulomas in the pleural biopsy in the absence 
of other pleural granulomatous diseases. Also classified in this group were patients with pulmonary tuberculosis demonstrated by Löwenstein culture in bronchopulmonary secretions, scant pleural fluid precluding pleural biopsy and a favourable clinical course after tuberculosis treatment.

2. Neoplastic pleural effusion. Cytological or histological diagnosis of neoplasm of the pleural space, or histological diagnosis of tumour in any other organ and no other cause of pleural effusion.

3. Parapneumonic effusion. Patients with cough, fever, a radiographic pulmonary infiltrate that disappeared with antibiotic treatment and a negative bacterial pleural culture. Empyema was considered in patients with either pus in the pleural cavity or a positive bacterial culture of the pleural fluid.

4. Miscellaneous. According to standard criteria for the diagnosis of other effusions [16].

5. Pleural effusion of nontuberculous, unknown aetiology. Patients with no known cause of pleural effusion, who had nonspecific pleuritis studied by pleural biopsy, thoracoscopy, thoracotomy or necropsy, as well as two negative Löwenstein cultures of the pleural fluid or tissue.

6. Transudate. Effusions were classified according to clinical and biochemical criteria [16].

Patients who could not be classified into any of these groups were excluded.

\section{Management of the samples and IFN- $\gamma$ assay}

Pleural fluid samples were collected in dry tubes. The samples were brought to the laboratory immediately, centrifuged for $10 \mathrm{~min}$ at $1,500 \times \mathrm{g}$, and then stored frozen at $-20^{\circ} \mathrm{C}$ until assayed.

IFN- $\gamma$ was measured by radioimmunoassay (RIA) (Centocor gamma interferon RIA). This system is a solidphase RIA based on the "forward sandwich" principle. Polystyrene beads, coated with one of the mouse monoclonal antibodies specific for human IFN- $\gamma$, were incubated with specimens. During this incubation, the IFN- $\gamma$ present in the specimen binds to the solid phase. Unbound material present in the specimen was removed by aspirating the fluid and washing the beads. Another monoclonal antibody against IFN- $\gamma$, labelled with ${ }^{125} \mathrm{I}$, was incubated with the beads. If IFN- $\gamma$ was bound to the beads, the radiolabelled anti-IFN- $\gamma$ then bound to the IFN- $\gamma$ on the beads. Unbound, labelled antibody was removed by aspiration. The bound radioactivity was determined by counting the beads in a well-type gammacounter. IFN- $\gamma$ concentration was expressed as units per millilitre.

\section{Statistical analysis}

The statistical significance of differences was evaluated with the Student's t-test or with one-way analysis of variance (ANOVA), in case of two or more groups, respectively. Sensitivity was calculated as: true-positive/ (true-positive + false-negative); specificity: true-negative/ (true-negative + false-positive); accuracy: (true-positive + true-negative) $/($ true-positive + true-negative + falsepositive + false-negative)[17].

\section{Results}

We measured the level of IFN- $\gamma$ in pleural fluid specimens from 397 patients. Nine patients were excluded because they could not be classified into any of the diagnostic groups; all of them had IFN- $\gamma$ levels below 1.8 $\mathrm{U} \cdot \mathrm{mL}^{-1}$. The 388 patients included were 254 males and 134 females, mean age 57 (range 15-95) yrs. The diagnostic breakdown of the patients is presented in table 1.

The mean IFN- $\gamma$ values and standard deviations for each group are presented in table 2. The differences between the group with tuberculous pleural effusion and the other groups were statistically significant $(\mathrm{p}<0.01)$. The human immunodeficiency virus (HIV) serology was tested in 50 of the patients who had pleural tuberculosis. There was no significant difference between IFN- $\gamma$ levels in the tuberculous pleural effusion of HIV-positive patients $(n=9)$ and of HIV-negative patients $(n=41)$ $(\mathrm{p}=0.26)$.

Table 1. - Aetiology of the effusions

\begin{tabular}{|c|c|}
\hline Aetiology & $\mathrm{n}$ \\
\hline Tuberculosis & 73 \\
\hline Neoplasms & 143 \\
\hline Lung & 48 \\
\hline Mesothelioma & 20 \\
\hline Lymphoma & 11 \\
\hline Breast & 8 \\
\hline Stomach & 5 \\
\hline Ovary & 4 \\
\hline Bladder & 3 \\
\hline Colon & 2 \\
\hline Kidney & 2 \\
\hline Pancreas & 2 \\
\hline Rectum & 2 \\
\hline Larynx & 1 \\
\hline Melanoma & 1 \\
\hline Thyroid & 1 \\
\hline Cervix uteri & 1 \\
\hline Vulva & 1 \\
\hline Suprarenal & 1 \\
\hline Agnogenic myeloid metaplasia & 1 \\
\hline Unknown & 29 \\
\hline Parapneumonic & 43 \\
\hline Miscellaneous & 40 \\
\hline Nontuberculous chylothorax & 5 \\
\hline Viral pleuropericarditis & 5 \\
\hline Postsurgery & 4 \\
\hline Uraemia & 4 \\
\hline Pulmonary embolism & 3 \\
\hline Pancreatitis & 3 \\
\hline Systemic lupus erythematosus & 3 \\
\hline Rheumatoid arthritis & 2 \\
\hline Trapped lung & 2 \\
\hline Nontuberculous pseudochylothorax & 1 \\
\hline Wegener's granulomatosis & 1 \\
\hline Parietal angioma & 1 \\
\hline Ovarian hyperstimulation syndrome & 1 \\
\hline Asbestos pleural effusion & 1 \\
\hline Postraumatic & 1 \\
\hline Liver transplantation & 1 \\
\hline Postpartum pleural effusion & 1 \\
\hline Rheumatic polymyalgia & 1 \\
\hline Nontuberculous unknown aetiology & 46 \\
\hline Transudates & 43 \\
\hline
\end{tabular}


Table 2. - Levels of IFN- $\gamma$ according to the cause of pleural effusion

\begin{tabular}{lrc}
\hline & $\begin{array}{c}\text { Pts } \\
\text { n }\end{array}$ & IFN- $\gamma$ \\
& U.mL-1 \\
\hline Tuberculous & 73 & $107.9 \pm 218.6^{\dagger}$ \\
$\quad$ HIV-positive & 9 & $73.5 \pm 97.3$ \\
HIV-negative & 41 & $135.6 \pm 281.1$ \\
Neoplastic & 143 & $1.0 \pm 0.5$ \\
Parapneumonic & 43 & $1.1 \pm 0.7$ \\
Miscellaneous & 40 & $1.0 \pm 0.6$ \\
Nontuberculous & 46 & $3.0 \pm 8.6$ \\
Transudates & 43 & $1.3 \pm 0.5$ \\
\hline
\end{tabular}

IFN- $\gamma$ : interferon- $\gamma$; Pts: patients; HIV: human immunodeficiency virus. ${ }^{\dagger}: \mathrm{p}<0.01$, compared to the nontuberculous groups.

Individual IFN- $\gamma$ values are shown in figure 1 . The operating characteristics of the test with different cutoff points are presented in table 3 . We chose $3.7 \mathrm{U} \cdot \mathrm{mL}^{-1}$ as the best cut-off point in the present population.

A group of patients without a definitive diagnosis of pleural effusion was included in this study. Thoracoscopy was performed in five of them, thoracotomy in three and necropsy in one patient. We are almost certain that these patients did not suffer from pleural tuberculosis. Of the other 37 patients: one pleural biopsy was performed in 14; two pleural biopsies in 19; and three pleural biopsies in four. Although it is unlikely that the cause of the effusion was tuberculosis [1], it may be possible that some of them had pleural tuberculosis. If the results are analysed after the exclusion of these 46 patients, with a 3.7 cut-off point, we obtain a sensitivity of 0.99 (95\% confidence interval (95\% CI) $0.93-1.00)$, and a specificity of 0.99 (95\% CI 0.97-1.00), and the difference is not significant.

Only one patient in the group with tuberculous pleural effusion had very low levels of IFN- $\gamma\left(0.8 \mathrm{U} \cdot \mathrm{mL}^{-1}\right)$. This patient was a female aged 23 yrs, without immunosuppression, who had granulomas on the pleural biopsy, and recovered completely after tuberculosis treatment. Her adenosine deaminase (ADA) level was $24 \mathrm{U} \cdot \mathrm{mL}^{-1}$, i.e. below our cut-off point for that enzyme $\left(33 \mathrm{U} \cdot \mathrm{mL}^{-1}\right)$.
Table 3. - Operating characteristics of interferon- $\gamma$ (IFN$\gamma$ ) as a test for pleural tuberculosis, with different cut-off points

\begin{tabular}{cccc}
\hline $\begin{array}{l}\text { Cut-off point } \\
\text { U.mL-1 }\end{array}$ & Sensitivity & Specificity & Accuracy \\
\hline 3.7 & $0.99(0.93-1.00)$ & $0.98(0.96-1.00)$ & 0.98 \\
5.0 & $0.97(0.90-1.00)$ & $0.99(0.97-1.00)$ & 0.98 \\
7.2 & $0.93(0.85-0.98)$ & $0.99(0.97-1.00)$ & 0.98 \\
9.0 & $0.90(0.81-0.96)$ & $0.99(0.98-1.00)$ & 0.98 \\
\hline
\end{tabular}

95\% confidence intervals are presented in parenthesis.

The nine HIV-positive patients in the present series all had IFN- $\gamma$ values above $3.7 \mathrm{U} \cdot \mathrm{mL}^{-1}$. Six of them had $<200 \mathrm{CD} 4+$ cells $\mu \mathrm{L}^{-1}$ in serum; two patients had 246 and 418 CD4+ cells $\mu \mathrm{L}^{-1}$, and CD4+ were not measured in one HIV-positive patient. The tuberculous group had another immunosuppressed patient. She was a liver transplant recipient, who had granulomas in the pleural biopsy. Löwenstein cultures of her pleural fluid and pleural tissue were negative. Her IFN- $\gamma$ level was $45.1 \mathrm{U} \cdot \mathrm{mL}^{-1}$, and the effusion disappeared after tuberculosis treatment.

Five patients from the nontuberculous groups had IFN$\gamma$ levels above the cut-off point. One had a squamous bronchogenic carcinoma. Another had a small-cell bronchogenic carcinoma and developed pneumonia with empyema, from which he died 3 days later. The third patient died during assessment and necropsy did not clarify the cause of effusion. The fourth patient had previously suffered from an incorrectly treated pulmonary tuberculosis, and the pleural effusion resolved spontaneously after two nondiagnostic pleural biopsies. The fifth patient died during the study after three nondiagnostic pleural biopsies; he also had high ADA levels in pleural fluid.

\section{Discussion}

In the present study, IFN- $\gamma$ levels have been found to be higher in tuberculous pleural effusion than in other types of pleural effusion, with a very good sensitivity

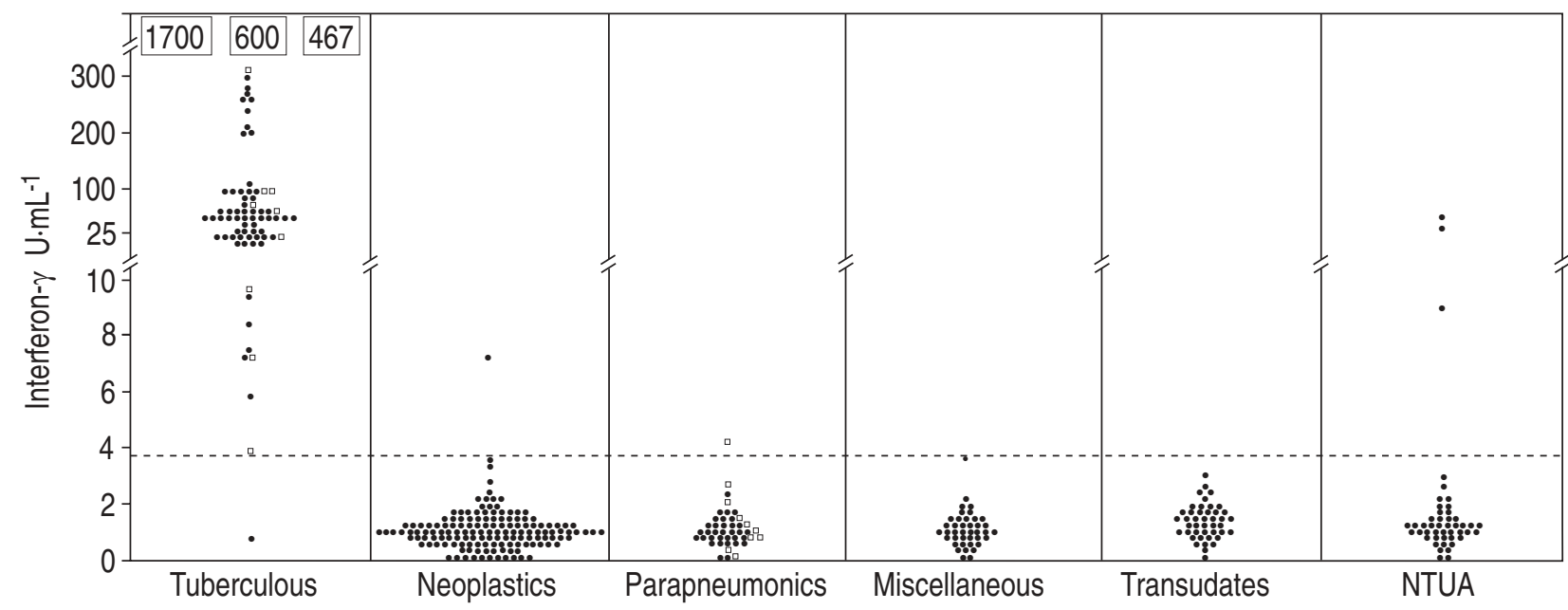

Fig. 1. - Individual interferon- $\gamma($ IFN- $\gamma$ ) values in the different diagnostic groups. NTUA: nontuberculous unknown aetiology. $\mathbf{~ : ~ H I V - p o s i t i v e ~}$ patients with pleural tuberculosis in the tuberculosis group, and empyematous effusions in the parapneumonic group. The broken horizontal line represents the $3.7 \mathrm{U} \cdot \mathrm{mL}^{-1}$ cut-off point. The numbers in the top left hand corner represent IFN- $\gamma$ values greater than $300 \mathrm{U} \cdot \mathrm{mL}^{-1}$. 
Table 4. - Summary of study results of the diagnostic value of IFN- $\gamma$

\begin{tabular}{|c|c|c|c|c|c|c|c|c|}
\hline $\begin{array}{l}\text { First } \\
\text { author }\end{array}$ & Year & [Ref.] & Assay & Cut-off & \multicolumn{2}{|c|}{$\begin{array}{c}\text { Pts } \\
n\end{array}$} & Sen & Spec \\
\hline RIBERA & 1988 & [8] & RIA & $2 \mathrm{U} \cdot \mathrm{mL}^{-1}$ & $\begin{array}{l}\text { TB } \\
\text { NTB }\end{array}$ & $\begin{array}{r}48 \\
114\end{array}$ & 1.00 & 1.00 \\
\hline VALDES & 1993 & [9] & ELISA & $140 \mathrm{pg} \cdot \mathrm{mL}^{-1}$ & $\begin{array}{l}\text { TB } \\
\text { NTB }\end{array}$ & $\begin{array}{r}35 \\
110\end{array}$ & 0.94 & 0.92 \\
\hline AOKI & 1994 & [10] & ELISA & $?$ & $\begin{array}{l}\text { TB } \\
\text { NTB }\end{array}$ & $\begin{array}{l}11 \\
28\end{array}$ & 1.00 & 1.00 \\
\hline Present study & & & RIA & $3.7 \mathrm{U} \cdot \mathrm{mL}^{-1}$ & $\begin{array}{l}\text { TB } \\
\text { NTB }\end{array}$ & $\begin{array}{r}73 \\
315\end{array}$ & 0.99 & 0.98 \\
\hline Total & & & & & $\begin{array}{l}\text { TB } \\
\text { NTB }\end{array}$ & $\begin{array}{l}167 \\
567\end{array}$ & 0.98 & 0.98 \\
\hline
\end{tabular}

IFN- $\gamma$ : interferon- $\gamma$; RIA: radioimmunoassay; ELISA: enzyme-linked immunosorbent assay; Sen: sensitivity; Spec: specificity; TB: tuberculous pleural effusion; NTB: nontuberculous pleural effusion; ?: no cut-off value given.

and specificity. Furthermore, the results were not different in immunocompetent and immunocompromised patients.

We reviewed the literature and have summarized the operating characteristics reported (table 4). The differences found in the diagnostic capacity of IFN- $\gamma$ might be due to the assay used (RIA or enzyme-linked immunosorbent assay (ELISA)), or to the range of diseases included in the studies. In addition, different cut-off levels were used, perhaps because of interlaboratory variability. Every laboratory should determine the most suitable cut-off point.

Only one patient in the tuberculous group had IFN- $\gamma$ levels below the cut-off value. Only two other patients from one series [9] have had false-negative results. Ribera et al. [8] found that small effusions had lower levels of IFN- $\gamma$ (but not significantly so). The patients with low IFN- $\gamma$ level in the study by VALDÉS et al. [9] had small effusions, but our patient with a low IFN- $\gamma$ level had a large effusion, and we were not able to identify any clinical, biochemical, or pathological difference between this patient and the other patients with pleural tuberculosis.

In 19 patients with tuberculosis, the first pleural biopsy was nondiagnostic (negative Löwenstein culture and no granulomas), but all of them had high IFN- $\gamma$ levels. The sensitivity of IFN- $\gamma$ was, thus, higher than the sensitivity of pleural biopsy.

The incidence of tuberculous pleural effusion is increased in HIV-positive patients, and it differs from tuberculous pleural effusion in HIV-negative patients [18]. No previous studies have reported IFN- $\gamma$ measurements in HIV-positive patients, so we feel that this is an important point of this study. As CD4+ lymphocytes are the source of IFN- $\gamma$ [14], it would be expected that IFN- $\gamma$ values in HIV-positive patients would be lower than those of immunocompetent patients. However, no such difference was observed: all nine HIV-positive patients had IFN- $\gamma$ levels over $3.7 \mathrm{U} \cdot \mathrm{mL}^{-1}$. This could have been explained if the patients had high CD4+ cell counts in serum, because tuberculous pleural effusion has a lower incidence in HIV-positive patients with low CD4+ lymphocyte counts [19]. Nevertheless, at least six of the nine HIV-positive patients had CD4+ cell counts under 200 cells $\cdot \mu \mathrm{L}^{-1}$. Another possibility is that the number of HIV-positive patients was too small to yield any difference. As it was, the diagnostic capacity of IFN- $\gamma$ was similar in the HIV-positive and HIV-negative patients, and most patients of both groups are far enough from the cut-off value. This is an advantage of IFN- $\gamma$ with respect to ADA, another marker of tuberculous pleural effusion, but one that differs significantly between HIV-positive and HIV-negative patients [20]. In addition, ADA levels have been found to be under the cutoff point in some HIV-positive patients [21, 22].

In the present study, only five patients without tuberculosis had IFN- $\gamma$ values above $3.7 \mathrm{U} \cdot \mathrm{mL}^{-1}$ in pleural fluid. Positive IFN- $\gamma$ results have been reported in previous studies in neoplasms, parapneumonic effusions, or pulmonary embolism $[8,9]$. Two of our patients belonged to these groups, and the three other patients had an idiopathic pleural effusion.

As RiBerA et al. [8] reported, IFN- $\gamma$ levels might also be elevated in autoimmune disorders. In addition, patients with rheumatoid arthritis and lymphoma usually have high pleural levels of ADA [23, 24]. Neither the two rheumatoid pleural effusions in this series nor the only patient previously reported [10] had IFN- $\gamma$ levels in excess of cut-off values. Similarly, none of our 11 non-Hodgkin's lymphomas and only one out of nine previously reported $[9,10]$, had high IFN- $\gamma$ levels. These findings suggest another advantage of IFN- $\gamma$ over ADA. In addition, vasculitides, such as Wegener's granulomatosis, (one case in the present study and one in the study by Aокі et al. [10]), or vascular connective tissue diseases, such as systemic lupus erythematosus (three cases in the present study and two in the literature [9]), also had IFN- $\gamma$ levels below the cut-off point. These data show that the IFN- $\gamma$ level in pleural fluid is not usually elevated in autoimmune diseases.

In conclusion, the level of interferon- $\gamma$ in pleural fluid is a good diagnostic marker of pleural tuberculosis, even in human immunodeficiency virus positive patients, and it may be superior to adenosine deaminase. A high level of interferon- $\gamma$ in the pleural fluid of a patient with a clinical picture suggestive of tuberculosis is virtually diagnostic.

Acknowledgement: The authors would like to thank R.W. Light for his careful reviewing of this manuscript. 


\section{References}

1. Light RW. Tuberculous pleural effusions. In: Light RW, ed. Pleural Diseases. 3rd edn. Baltimore, Williams \& Wilkins, 1995; pp. 154-166.

2. Barnes PF, Fong S, Brennan PJ, Twomey PE, Mazumder A, Modlin RL. Local production of tumor necrosis factor and IFN- $\gamma$ in tuberculous pleuritis. J Immunol 1990; 145: 149-154.

3. Shimokata K, Saka H, Murate T, Hasegawa Y, Hasegawa T. Cytokine content in pleural effusion. Chest 1991; 99: 1103-1107.

4. Maeda J, Ueki N, Iwahashi N, Nakano T, Hada T, Higashino K. Local production and localization of transforming growth factor-beta in tuberculous pleurisy. Clin Exp Immunol 1993; 92: 32-38.

5. Idell S. Granulomatous diseases of the pleura. Semin Respir Crit Care Med 1995; 16: 340-345.

6. Escudero Bueno C, García Clemente M, Cuesta Castro $\mathrm{B}$, et al. Cytologic and bacteriologic analysis of fluid and pleural specimens with Cope's needle. Arch Intern Med 1990; 150: 1190-1194.

7. Fontan Bueso J, Verea Hernando H, Pérez García-Buela J, Domínguez Juncal L, Martín Egaña MT, Montero Martínez MC. Diagnostic value of simultaneous determination of pleural adenosine deaminase and pleural lysozyme/serum lysozyme ratio in pleural effusions. Chest 1988; 93: 303-307.

8. Ribera E, Ocaña I, Martinez-Vázquez JM, Rossell M, Español T, Ruibal A. High level of interferon gamma in tuberculous pleural effusion. Chest 1988; 93: 308-311.

9. Valdés L, San José E, Alvarez D, et al. Diagnosis of tuberculous pleurisy using the biologic parameters adenosine deaminase, lysozyme, and interferon-gamma. Chest 1993; 103: 458-465.

10. Aoki Y, Katoh O, Nakanishi Y, Kuroki S, Yamada H. A comparison study of IFN- $\gamma$, ADA, and CA 125 as diagnostic parameters in tuberculous pleuritis. Respir Med 1994; 88: 139-143.

11. Echave Sustaeta J, Villena V, Izquierdo M, et al. Tumor necrosis factor-alpha in patients with pleural effusion. Eur Respir J 1993; 6 (Suppl. 17): 505s.

12. Caminero JA, Rodriguez de Castro F, Carrillo T, Diaz F, Rodriguez Bermejo JC, Cabrera P. Diagnosis of pleural tuberculosis by detection of specific IgG anti-antigen 60 in serum and pleural fluid. Respiration 1993; 60: $58-62$.
13. Orme IM, Miller ES, Roberts AD, et al. T-lymphocytes mediating protection and cellular cytolysis during the course of Mycobacterium tuberculosis infection. $J$ Immunol 1992; 148: 189-196.

14. Shimokata K, Kishimoto H, Takagi E, Tsunekawa H. Determination of the T-cell subset producing gammainterferon in tuberculous pleural effusion. Microbiol Immunol 1986; 30: 353-361.

15. López Encuentra A, Martínez Cruz R, Rodriguez de Castro F. Derrames pleurales. In: Martín Escribano P, López Encuentra A, eds. Diagramas. Neumología. Madrid, Idepsa, 1989; pp. 136-143.

16. Light RW. Approach to the patient. In: Light RW, ed. Pleural Diseases. 3rd edn. Baltimore, Williams \& Wilkins, 1995; pp. 75-82.

17. Griner PF, Mayewski JR, Mushlin AI, Greenland P. Selection and interpretation of diagnostic tests and procedures: principles and applications. Ann Intern Med 1981; 94: 557-592.

18. Relkin F, Aranda CP, Garay SM, Smith R, Berkowitz KA, Rom WN. Pleural tuberculosis and HIV infection. Chest 1994; 105: 1338-1341.

19. Jones BE, Young SMM, Antoniskis D, Davidson PT, Framer F, Barnes PF. Relationship of the manifestations of tuberculosis to CD4 cell counts in patients with human immunodeficiency virus infection. Am Rev Respir Dis 1993; 148: 1292-1297.

20. Hsu WH, Chiang CD, Huang PL. Diagnostic value of pleural adenosine deaminase in tuberculous effusions of immunocompromised host. J Formos Med Assoc 1993; 92: 668-670.

21. Villena V, Echave-Sustaeta J, López Encuentra A, Martín Escribano P, Navarro JA. Low ADA levels in pleural tuberculosis in HIV-seropositive patients. Rev Clin Esp 1994; 194: 382.

22. Villena V, Navarro Gonzálvez JA, García Benayas C, et al. Rapid automated determination of adenosine deaminase and lysozyme for differentiating tuberculous and nontuberculous pleural effusions. Clin Chem 1996; 42: 218-221.

23. Ocaña I, Ribera E, Martínez-Vázquez JM, et al. Adenosine deaminase activity in rheumatoid pleural effusion. Ann Rheum Dis 1988; 47: 394-397.

24. Fernández B de Quirós J, Susano RC, Talenti M, Rodríguez C. Adenosine deaminase in tumors: a marker of the pleural invasion of lymphoproliferative processes? Med Clin (Barc) 1992; 98: 276-277. 